\title{
Factors Affecting Diametral Tensile Strength of Microfilled Dental Composites
}

\author{
Jyongsik JANG* and Sangwoo KIM \\ Department of Chemical Technology, Seoul National University, \\ San 56-1, Shinlimdong Kwanakgu, Seoul, Korea
}

(Received May 19, 1995)

\begin{abstract}
Microfilled composites were fabricated by curing with visible light. Diametral tensile strength (DTS) of the microfilled composites was measured, and the effects of several factors on DTS were examined. The factors were silane coupling agent concentration, silica content, the composition of matrix resin, and curing time. Silane coupling agent concentration and the interfaces of the microfilled composites were mainly investigated. IR and SEM were used for analysis. Silane coupling agent concentration was the factor most affecting DTS, and maximum DTS was observed at $5.0 \mathrm{wt} \%$ concentration. In addition, DTS of the microfilled composites had linear relationships with silica content and curing time.

KEY WORDS Dental Composite / Diametral Tensile Strength / 2,2'-Bis[4-(methacryloxy-2-hydroxypropoxy)phenyl] / Fumed Silica / Silane Coupling Agent / Interfacial Bonding /
\end{abstract}

Dental composites are substitutes for amalgam and silicate cement in dental restorative materials. ${ }^{1,2}$ Dental composites have many advantages over other restorative materials, such as good handling characteristics, good adhesion to dentin and enamel, easiness of rebuilding, and so on. Therefore, study on and applications of those have become more important. ${ }^{3-5}$ Dental composites are largely divided into two categories by their filler particle size. One is the macrofilled composite containing fillers of over $1 \mu \mathrm{m}$ in diameter, and the other is the microfilled composite having submicrofillers. Fumed silica of about $0.04 \mu \mathrm{m}$ diameter is usually used as submicrofiller. The microfilled composite has good polishability and aesthetic merits, and of more importance in anterior teeth. $^{6-10}$

Tensile strength is one of the most important properties for evaluating dental composites. Because of easy evaluation and specimen size, diametral tensile strength (DTS) has been mainly used to measure the tensile strength of dental composites. ${ }^{11-14}$ Generally, the tensile strength of dental composites is affected by several factors, especially characteristics of the interface between the filler and matrix resin. ${ }^{15,16}$ The surface of a filler such as silica, glass bead, and quartz, is usually treated with silane coupling agents to improve interfacial bonding between the filler and matrix resin. The tensile strength of dental composites may be mostly influenced by the interfacial bondings between the filler, matrix and silane coupling agent, and silane coupling agent concentration is one of the most important factors affecting the mechanical properties of dental composites. Therefore, it is important to analyze the interfacial bonding characteristics of dental composites by Fourier Transform Infrared Spectroscopy (FT-IR), Scanning Electron Microscopy (SEM), and so on. Such factors as filler content, matrix composition, and curing time also influence the tensile strength of dental composites. There is limited information concerning the effects of these factors on the tensile strength, interfacial bonding characteristics, and silane coupling agent concentration. ${ }^{11-14}$

* To whom correspondence should be addressed.
Therefore, it is essential to investigate the influence of these several factors on the tensile strength of dental composites. The purpose of this study is not only to evaluate several factors on the DTS of microfilled dental composites cured by visible light, but improve the mechanical properties of dental restorative composites. In addition, spectroscopic and morphological studies of dental restorative composites have been carried out to understand interfacial phenomena between fillers and matrix resins.

\section{EXPERIMENTAL}

\section{Materials}

2,2'-Bis[4-(methacryloxy-2-hydroxy-propoxy)-phenyl]propane (BIS-GMA) was used as a matrix resin and triethyleneglycoldimethacrylate (TEGDMA) as a diluent to fabricate dental restorative materials. 2,2'-Bis(4-methacryloxyethoxyphenyl)propane (Bis-MEPP) was used as a matrix resin to be compared with BIS-GMA. The matrix resins were supplied by Shin-Nakamura Chemical Company. Figure 1 shows the molecular structures of the matrix resins.

The matrix resins were cured using the light curing system containing camphorquinone (CQ, $\alpha-1,2$ diketone) as a photosensitizer and dimethylaminoethylmethacrylate (DMAEMA) as an amine reducing agent. The submicrofiller was fumed silica (Aerosil OX-50, Degussa) with a primary particle size of $0.04 \mu \mathrm{m}$. The properties of Aerosil OX-50 are listed in Table I. The silane coupling agent used for filler surface treatment was $\gamma$-methacryloxypropyl trimethoxy silane ( $\gamma$-MPS).

\section{Sample Preparation}

The silica surface was treated with $\gamma$-MPS solution. $\gamma$ MPS was prehydrolyzed in aqueous solution of $70 \mathrm{wt} \%$ ethanol $/ 30 \mathrm{wt} \%$ de-ionized water $(\mathrm{pH}=3.5)$ for one hour. After mixing silica with hydrolyzed $\gamma$-MPS solution, the mixture was dried for over 20 days at room temperature. Dental restorative composites were fabricated with the silane treated fumed silica as a filler and the mixture of TEGDMA and BIS-GMA or Bis-MEPP as the matrix 


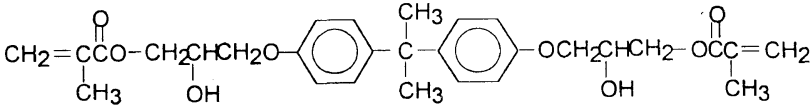

2,2'-bis-[4-(methacryloxy-2-hydroxy-propoxy)-phenyl]-propane (BIS-GMA)

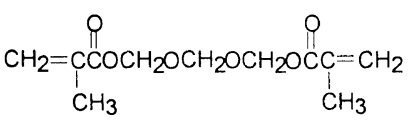

triethylene glycol dimethacrylate (TEGDMA)

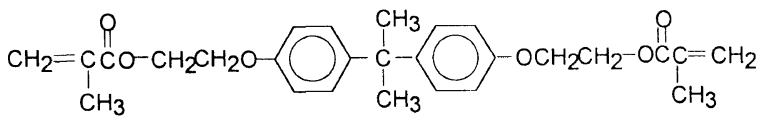

2,2'-bis(4-methacryloxyethoxyphenyl)propane (Bis-MEPP)

Figure 1. Molecular structures of matrix resins.

Table I. Properties of aerosil OX-50

$\begin{array}{lc}\text { Primary particle size } / \mathrm{nm} & 40 \\ \text { BET surface area } / \mathrm{m}^{2} \mathrm{~g}^{-1} & 50 \\ \text { Moisture }\left(2 \mathrm{~h} \text { at } 105^{\circ} \mathrm{C}\right) / \% & <1.5 \\ \text { Ignition loss }\left(2 \mathrm{~h} \text { at } 1000^{\circ} \mathrm{C}\right) / \% & <1\end{array}$

resin.

Microfilled composites were cured by visible light system in a Teflon-coated metal mold. Cured microfilled composites were stored at room temperature for over one week before DTS measurement. Visible light curing unit was XL-1000 of 3M company. It had a visible light range of $400-500 \mathrm{~nm}$ and a maximum peak near $470 \mathrm{~nm}$ wavelength (blue light).

\section{Measurements}

The factors and elementary conditions are listed in Table II. Elementary conditions and factors were determined in commercial microfilled composites. ${ }^{17,18}$ With the condition of the only one factor changed and the others fixed, the effects of this factor on DTS were evaluated. DTS was measured according to the American Dental Association specification No. 27, and by compressive testing of cylinder type specimen $(3 \mathrm{~mm}$ high, $6 \mathrm{~mm}$ diameter) at $1 \mathrm{~cm} \mathrm{~min}^{-1}$ crosshead speed. ${ }^{19}$ Figure 2 shows the schematic diagram of DTS test. DTS was calculated as,

$$
\mathrm{DTS}=2 \cdot P / \pi \cdot D \cdot T
$$

where $P$, load at fracture; $D$, diameter; $T$, thickness. The universal testing machine was Instron 4202 and load cell was $1000 \mathrm{~kg}$. FT-IR (Bomem MB-100) and SEM (JEOL JSM-35) were used to investigate the interfacial phenomena of dental composites. The adsorption behavior of $\gamma$-MPS on the silica surface was investigated by FT-IR transmission spectra. Silane treated silica was pressed to make a thin wafer. The thin wafer was used to measure the FT-IR transmission spectrum of the silane treated silica surface. The fracture surface of sample for SEM measurement was coated with gold to prevent electron beams from irregular diffraction.
Table II. Factors and elementary conditions of this experiment

\begin{tabular}{ll}
\hline \multicolumn{1}{c}{ Factors } & Conditions \\
\hline Silica & $50 \mathrm{wt} \%$ \\
$\gamma$-MPS & $0.5 \mathrm{wt} \%$ \\
Camphorquinone & $0.4 \mathrm{wt} \%$ \\
DMAEMA & $0.4 \mathrm{wt} \%$ \\
The weight ratio of BIS-GMA and TEGDMA & $5 / 5$ \\
Radiation time & $40 \mathrm{~s}$ \\
\hline
\end{tabular}

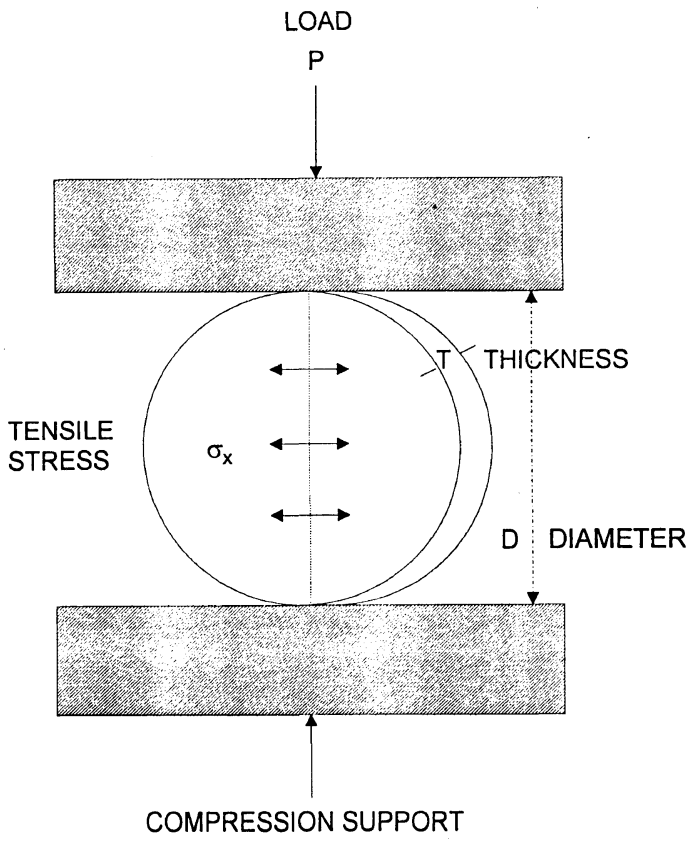

Figure 2. Testing scheme of diametral tensile strength.

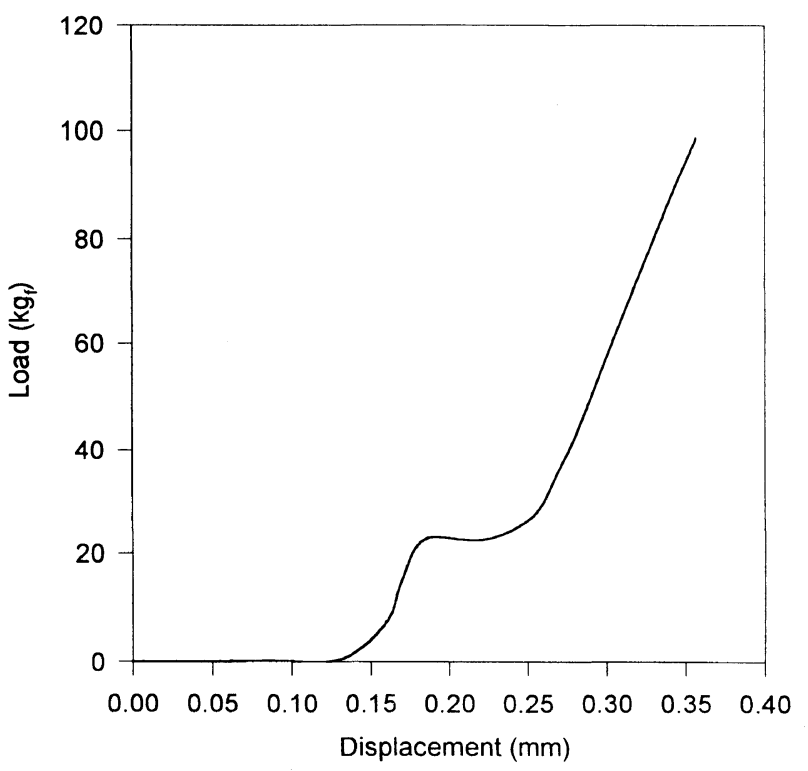

Figure 3. Load-displacement curve of DTS.

\section{RESULTS AND DISCUSSION}

In general, valid DTS measurement cannot be achieved unless the specimen shows brittle behavior. ${ }^{11}$ Figure 3 shows the load-displacement curve of a microfilled composite containing $50 \mathrm{wt} \%$ silica. As shown in Figure 3, the specimen showed brittle behavior. In addition, if 
Table III. Effect of crosshead speed on DTS (MPa)

\begin{tabular}{lccc}
\hline & \multicolumn{3}{c}{ Silica content } \\
\cline { 2 - 4 } Crosshead speed & $40 \%$ & $50 \%$ & $60 \%$ \\
\hline $0.5 \mathrm{~mm} \mathrm{~min}^{-1}$ & 31.44 & 34.10 & 35.71 \\
$10 \mathrm{~mm} \mathrm{~min}^{-1}$ & 33.28 & 36.49 & 38.63 \\
\hline
\end{tabular}

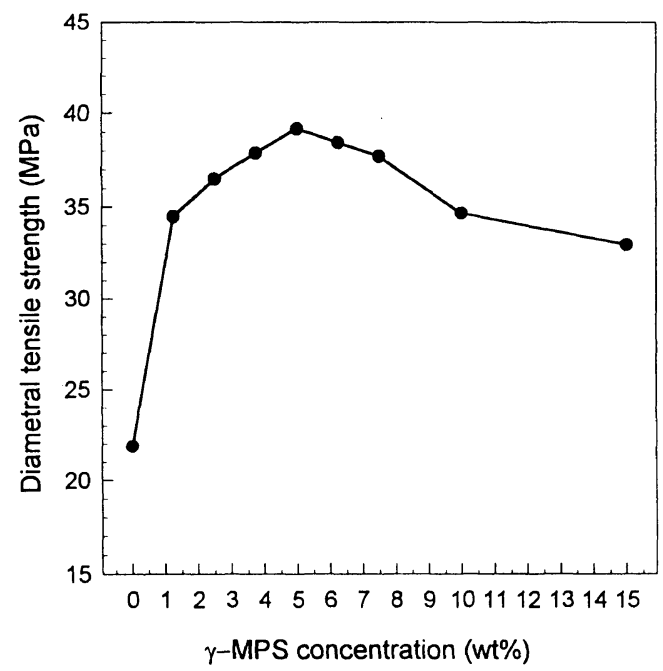

Figure 4. DTS as a function of $\gamma$-MPS concentration (silica based).

brittleness was slight, the dependency of DTS on crosshead speed decreased, as shown in Table III. The crosshead speed did not make DTS different greatly at any silica content, and differences were within $10 \%$ deviation. By these results, microfilled composites showed brittle behavior and valid DTS measurements.

Figure 4 shows DTS of the microfilled composites tested at different $\gamma$-MPS concentrations. The specimen treated with $\gamma$-MPS showed much greater DTS than untreated ones. DTS of microfilled composites increased with $\gamma$-MPS concentration and maximum was observed at $5.0 \mathrm{wt} \%$ silane concentration (silica filler based). This can be explained by the fact that effective bonds are formed at the interface between the filler and matrix resin by introducing methacrylate functional groups on the silica surface. The results of Figure 4 show $\gamma$-MPS concentration to affect DTS most. However, DTS over $5.0 \mathrm{wt} \%$ silane concentration decreased gradually. This trend can be explained by the FT-IR analysis of silane treated silica surface and SEM micrographs of the fractured composite surfaces.

Figure 5 shows the FT-IR spectra of the silane treated silica surface. Adsorption behavior on the silica surface at different $\gamma$-MPS concentrations was investigated for interfacial phenomena between the silica surface and matrix resin. The band at $1640 \mathrm{~cm}^{-1}$ shows the aliphatic $\mathrm{C}=\mathrm{C}$ stretching mode, and the band at $1700 \mathrm{~cm}^{-1}$ is due to the carbonyl groups hydrogen-bonded with hydroxyl groups of the silica surface. These peaks resulted from the methacrylate groups of $\gamma$-MPS. As the concentration of $\gamma$-MPS increased, bands at $1640 \mathrm{~cm}^{-1}$ and $1700 \mathrm{~cm}^{-1}$ increased, and the peak at $1720 \mathrm{~cm}^{-1}$ began to appear in the (B) spectrum. This band at $1720 \mathrm{~cm}^{-1}$ results from the free carbonyl groups of $\gamma$-MPS not hydrogen-bonded with hydroxyl groups. This shows that multilayers of $\gamma$ -

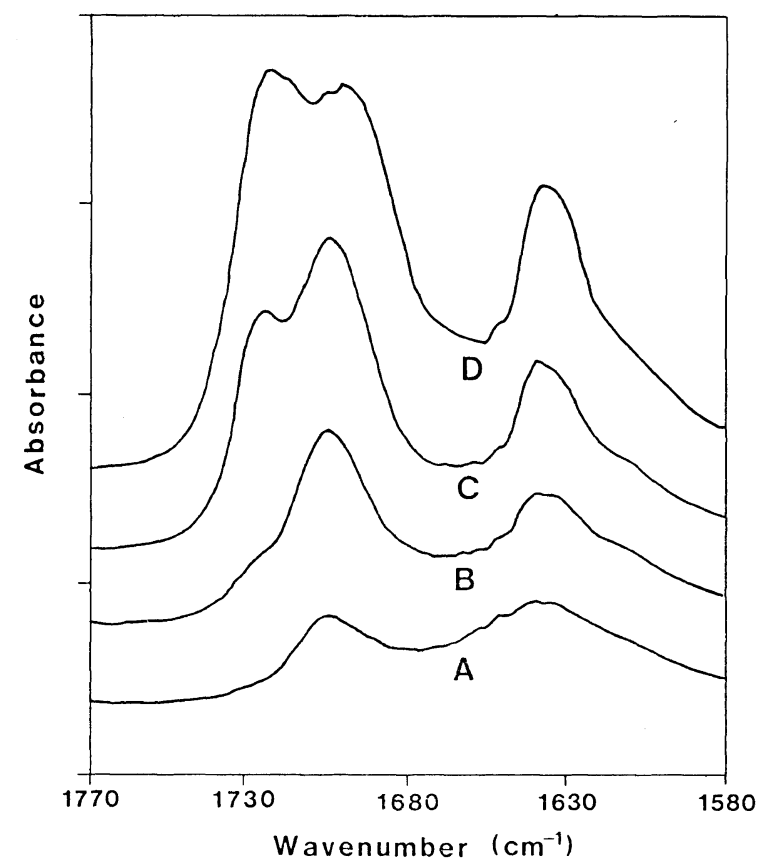

Figure 5. FT-IR spectra of silane treated silica surface. $\gamma$-MPS concentration in silane solution $(\mathrm{wt} \%$ ): (A) 1.25 ; (B) 2.5 ; (C) 5.0 ; (D) 10.0 .

MPS began to form on the silica surface. ${ }^{16}$ As shown in (C), (D) spectra, the free carbonyl groups and multilayers of $\gamma$-MPS increased on the silica surface with the concentration of $\gamma$-MPS increasing.

The monolayer coverage concentration of $\gamma$-MPS can be defined as $\%$ treatment at which free carbonyl groups just begin to appear. ${ }^{20}$ Therefore, the monolayer coverage concentration determined by IR spectroscopy is about $2.5 \mathrm{wt} \%$ [(B) spectrum in Figure 5]. The area of one $\gamma$-MPS molecule adsorbed on the surface is assumed to be $6 \times 10^{-19} \mathrm{~m}^{2} .^{21}$ This can be converted to an ideal specific surface area by the following calculation:

$$
\begin{aligned}
& \frac{6 \times 10^{-19}\left[\mathrm{~m}^{2} \text { molecule }{ }^{-1}\right] \times 6.023 \times 10^{23}\left[\text { molecule mol }^{-1}\right]}{248.35\left[\mathrm{~g} \mathrm{~mol}^{-1}\right]} \\
& =1455\left[\mathrm{~m}^{2} \mathrm{~g}^{-1}\right]
\end{aligned}
$$

248.35 is the molecular weight of $\gamma$-MPS. The specific area of Aerosil OX-50 is $50 \mathrm{~m}^{2} \mathrm{~g}^{-1}$. By these data, the monolayer coverage concentration of $\gamma$-MPS was calculated as $3.4 \mathrm{wt} \%$, which is not different greatly with the above experimental result. Ideally, in case of the monolayer of $\gamma$-MPS which interlinks both matrix and filler by tight chemical bonding, DTS can be maximum. The optimum $\gamma$-MPS concentration for DTS $(5.0 \mathrm{wt} \%)$, however, is slightly higher than both the experimental and calculated monolayer coverage concentrations. As shown in the (C) spectrum of Figure 5, multilayers of $\gamma$-MPS formed sufficiently on the silica surface at that concentration. The multilayers of $\gamma$-MPS interlinked by loose physical bondings can cause the reduction in DTS.

This can be explained by chemical bonding theory and surface wettability theory. ${ }^{16,22}$ Microfilled composites are highly loaded with submicrofillers which increase greatly the viscosity of composite paste. Its high viscosity makes the dispersion of silica particles difficult and causes poor interfacial bondings between matrix and filler. $\gamma$-MPS slightly above monolayer coverage concentration 




(A)

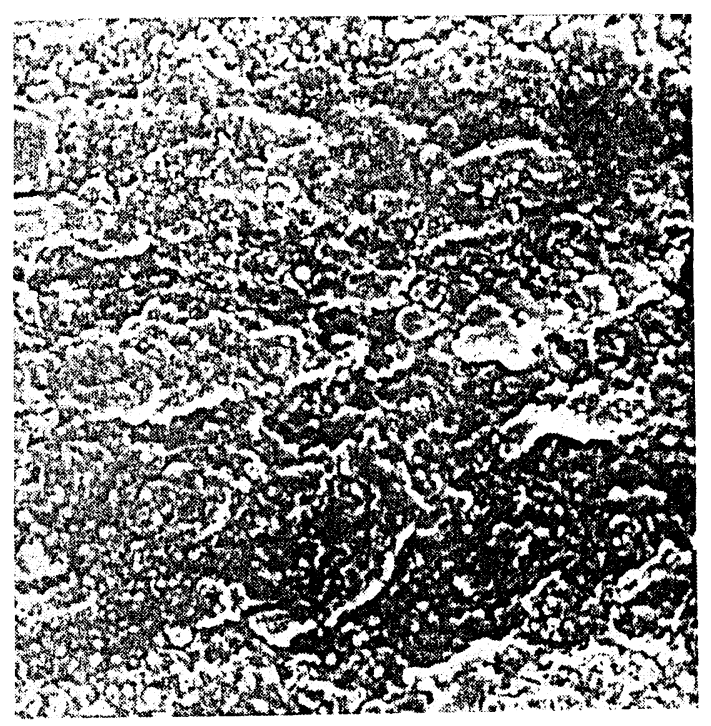

(B)
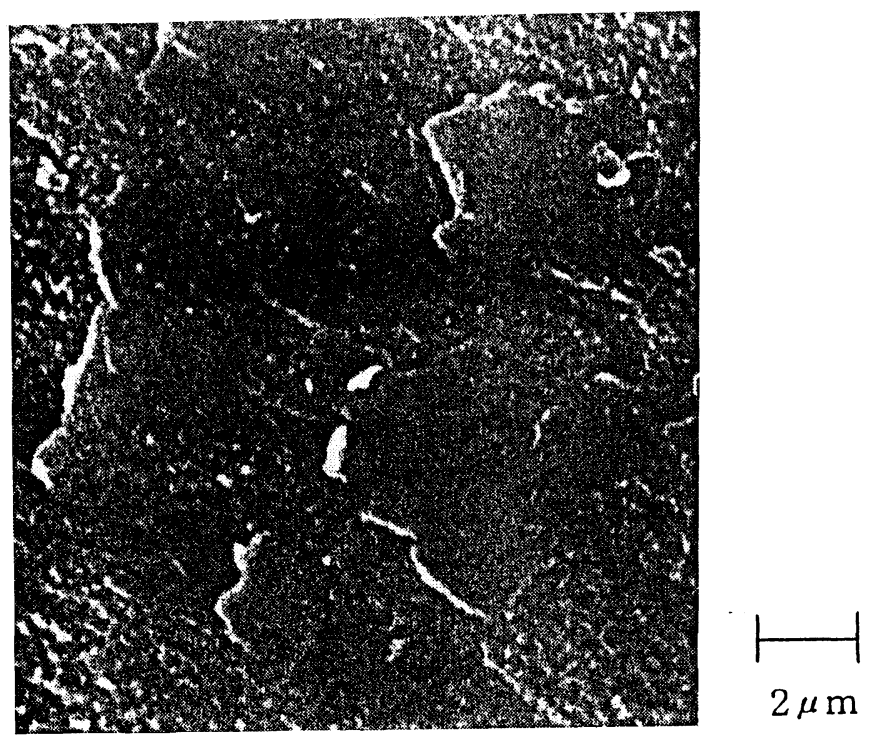

$2 \mu \mathrm{m}$

(C)

Figure 6. SEM micrographs of microfilled composites as a function of $\gamma$-MPS concentration in silane solution. (A) untreated; (B) $2.5 \mathrm{wt} \%$; (C) $5.0 \mathrm{wt} \%$.

reduces more effectively the viscosity of the microfilled composite paste and increases the wettability of the silica particles in paste. The bonding and adhesion strength of the microfilled composite interface are promoted by the good dispersion and wetting of the silica particles.

However, above the optimum concentration, DTS of microfilled composites decreased by the excessive lubrication effect of $\gamma$-MPS. The specific wetting surface area (WS) of $\gamma$-MPS is $314 \mathrm{~m}^{2} \mathrm{~g}^{-1} \cdot{ }^{23} \mathrm{WS}$ is the ellipsometrically determined value of uniform deposition layer. $\gamma$ MPS concentration necessary to obtain minimum uniform multilayer coverage can be calculated by WS. The calculated result was $15.9 \mathrm{wt} \%$. As shown in Figure 4, DTS was $32.94 \mathrm{MPa}$ near this concentration $(15.0 \mathrm{wt} \%)$, or $6.23 \mathrm{MPa}$ lower than the maximum. So, the uniform multilayer of $\gamma$-MPS reduced the mechanical properties of microfilled composites.

The morphology of microfilled composite fracture surfaces was analyzed by SEM. Figure 6 shows SEM photographs of the untreated and silane treated fracture surfaces. As shown in Figure 6, silica particles exist as agglomerates of about $0.1-0.2 \mu \mathrm{m}$ diameter in dental composites. In case of an untreated fracture surface [Figure 6(A)], silica particles were seperated from the matrix resin and protruded from the fracture surface. Therefore, unmodified composites are thought to show interfacial failure. In contrast, in case of the silane treated composite [Figure 6(B)], the number of protruded silica particles on the surface decreased. This suggests that cohesive failure occurred. This was prominent at $5.0 \mathrm{wt} \%$ concentration [Figure $6(\mathrm{C})]$. These results correspond to the fact that the maximum DTS is shown at $5.0 \mathrm{wt} \%$ $\gamma$-MPS concentration.

DTS at different silica contents are shown in Figure 7. DTS showed a linear relation with silica content. The increase of DTS by silica content was less than that by 


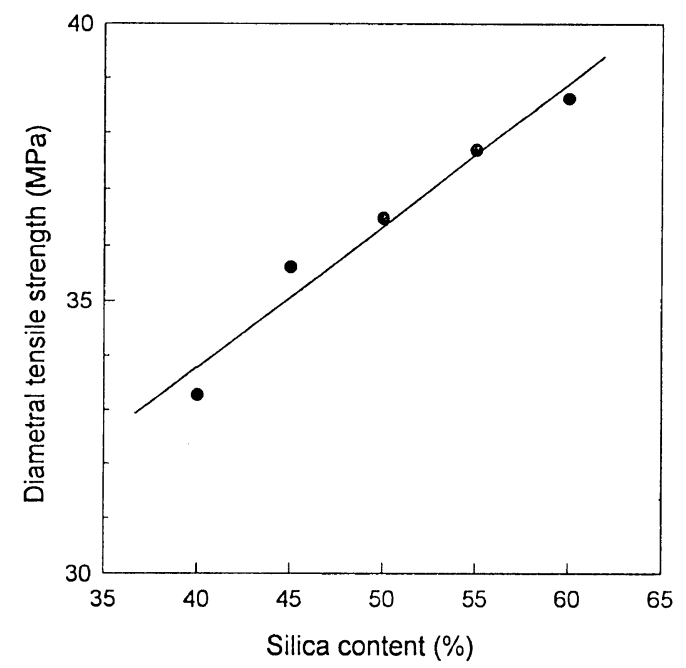

Figure 7. DTS as a function of silica content.

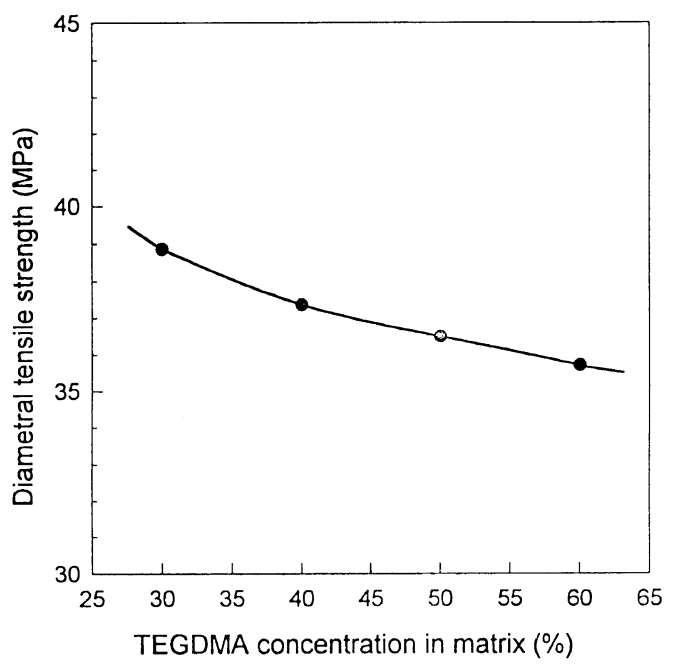

Figure 8. DTS as a function of TEGDMA concentration.

Table IV. Effect of resin type on DTS

\begin{tabular}{ccc}
\hline Resin type & $\begin{array}{c}\text { BIS-GMA/TEGDMA } \\
(5 / 5)^{\mathrm{a}}\end{array}$ & $\begin{array}{c}\text { Bis-MEPP/TEGDMA } \\
(5 / 5)^{\mathrm{a}}\end{array}$ \\
\hline DTS (MPa) & 36.49 & 32.71 \\
\hline
\end{tabular}

${ }^{a}$ Weight ratio.

$\gamma$-MPS concentration. This is consistent with the fact that silane concentration has the greatest influence on the tensile strength of composites and that filler content has more influence on compressive strength than tensile strength.

Figure 8 shows the DTS of different TEGDMA concentrations in matrix resin. As TEGDMA concentration decreased, DTS of dental composites increased. This may be attributed to the fact that BIS-GMA having rigid benzene rings and hydrogen bonded hydroxyl groups shows better mechanical properties than TEGDMA having flexible ether linkages (Figure 1). DTS of BISGMA was compared with that of Bis-MEPP in Table IV. As shown in Table IV, BIS-GMA/TEGDMA was superior to Bis-MEPP/TEGDMA in dry DTS. This suggests that the mechanical properties of BIS-GMA with hydrogen bondings are better than those of Bis-

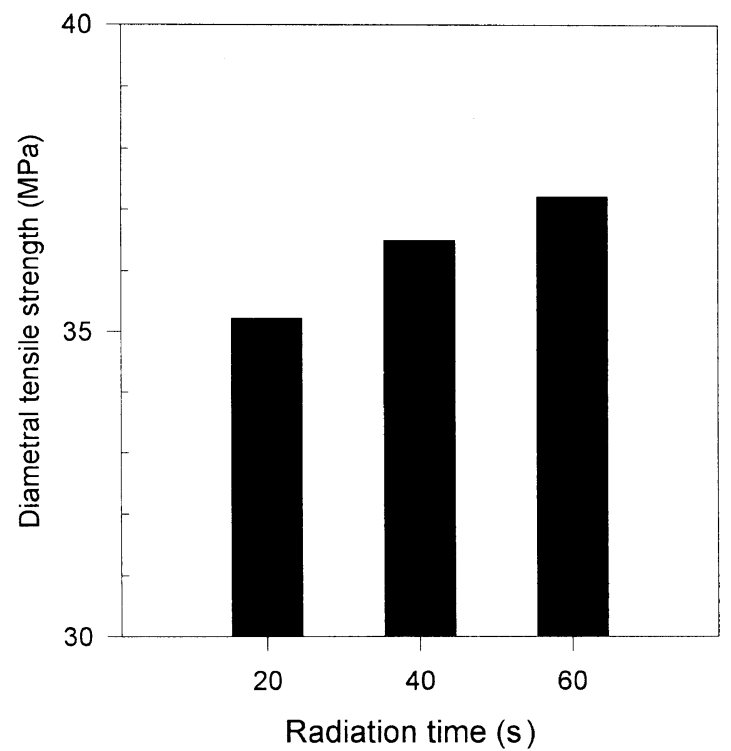

Figure 9. Relation between DTS and radiation time.

MEPP without hydrogen bonded hydroxyl groups.

Figure 9 shows the effects of visible light radiation time on DTS of microfilled composites. The radiation time had a linear relation with the degree of conversion (DC). DC means the conversion ratio of aliphatic $\mathrm{C}=\mathrm{C}$ to $\mathrm{C}-\mathrm{C}$ in microfilled composites. ${ }^{24}$ Figure 9 thus shows the relation between DC and DTS of composites. As shown in Figure 9, as radiation time increased, DTS also increased. This is consistent with the fact that the more DC increases, the better are the mechanical properties and dimensional stability of a composite.

\section{CONCLUSIONS}

DTS of visible light cured microfilled composites were investigated and factors affecting the DTS were considered. The following conclusions were obtained from the results:

1) Microfilled composites showed brittle behaviors through the load-displacement curve, and the validity of DTS measurements was proved.

2) $\gamma$-MPS concentration affected DTS the most. DTS was influenced by the adsorption characteristics of $\gamma$ MPS on the silica surface. Maximum DTS was shown at $5.0 \mathrm{wt} \% \gamma$-MPS concentration.

3) DTS of the microfilled composites had a linear relation with silica content. DTS was less influenced by silica content than $\gamma$-MPS concentration.

4) Mechanical properties of BIS-GMA were superior to TEGDMA and Bis-MEPP.

5) A linear relation between DC and DTS of microfilled composites was found. This shows that the more DC increase, the better are the mechanical properties of a microfilled composite.

\section{REFERENCES}

1. R. L. Bowen, U.S. Patent No. 3,066,112 (1962)

2. R. L. Bowen, J. Am. Dent. Assoc., 66, 57 (1963).

3. R. W. Phillips, "Skinner's Science of Dental Materials," 8th ed, Igaku-Shoin/Saunders, Philadelphia, PA, 1982, pp 177-247.

4. D. F. Williams, Ed., "Materials Science and Technology, Vol. 
14, Medical and Dental Materials," VCH, Cambridge, UK, 1992 pp 209-258.

5. R. G. Craig, "Restorative Dental Materials," 8 th ed., CV Mosby, St. Louis, MI, 1989, pp 514-520.

6. G. Willems, P. Lambrechts, M. Braem, J. P. Celis, and G. Vanherle, Dent. Mater., 8, 310 (1992).

7. H. Hosoda, T. Yamada, and S. Inokoshi, J. Prosth. Dent., 64, 669 (1990)

8. F. Luts and R. W. Philips, J. Prosth. Dent., 50, 480 (1983).

9. S. C. Bayne, H. O. Heymann, and E. J. Swift, Jr., J. Am. Dent. Assoc., 125, 687 (1994).

10. Counsil on Dental Materials, Instruments, and Equipment, $J$. Am. Dent. Assoc., 105, 488 (1982).

11. R. W. Pan, R. G. Craig, and J. A. Tesk, Dent. Mater., 3, 46 (1987).

12. A. Peutzfeld and L. Junggreen, Scand. J. Dent. Res., 100, 181 (1991).

13. W. W. Johnson, V. B. Dhuru, and W. A. Brantley, Dent. Mater., 9, 95 (1993).

14. O. Zidan, E. Asmussen, and K. D. Jørgensen, Scand. J. Dent. Res., 88, 285 (1980).

15. H. Ishida and G. Kumar, Ed., "Molecular Characterization of
Composite Interfaces," Plenum Press, New York, N.Y., 1985, pp 13-23.

16. J. Jang, "The adhesion promotion of composite interface and corrosion protection for metal surfaces by using silane derivatives," PhD Thesis, Case Western Reserve University, 1988.

17. M. Taira, H. Urabe, T. Hirose, K. Wakasa, and M. Yamaki, $J$. Dent. Res., 67, 22 (1988).

18. I. E. Ruyter and I. J. Sjøvik, Acta Odontol. Scand., 39, 133 (1981).

19. American Dental Association Specification No. 27 for direct filling resins, J. Am. Dent. Assoc., 94, 1191 (1977).

20. H. Ishida and J. D. Miller, Proceedings of 38th Annual Technical Conference, Reinforced Plastics/Composites Institute, SPI, Section 4-E, 1983.

21. J. D. Miller and H. Ishida, Surface Sci., 148, 601 (1984).

22. E. P. Plueddemann, "Silane Coupling Agents," Plenum Press, New York, N.Y., 1982.

23. R. Anderson, B. Arkles, and G. L. Larson, "Silicon Compounds-Resgister and Review," Petrarch Systems Silanes \& Silicones Group, Bristol, PA, 1987.

24. J. L. Ferracane and E. H. Greener, J. Dent. Res., 63, 1093 (1984). 